\title{
Negotiating place through food and drink: Experiencing home and away
}

\author{
Toya Bezzola \& Peter Lugosi
}

\author{
Oxford School of Hospitality Management \\ Oxford Brookes University \\ Gipsy Lane \\ Oxford \\ OX3 OBP \\ United Kingdom \\ plugosi@brookes.ac.uk
}

\begin{abstract}
Bezzola, T. \& Lugosi, P. (2018) Negotiating place through food and drink:
Experiencing home and away. Tourist Studies.

(Please consult the final published version if citing.)
\end{abstract}

\begin{abstract}
This study examines how food and drink-related practices mediate tourists' experiences in destinations. Adopting an interpretivist approach, and drawing on content analysis of travel blogs, the paper contributes to knowledge by demonstrating how the production and consumption of food and drink are used to negotiate feelings, memories and encounters in places. More specifically, we distinguish between three areas of practice: firstly, how situational control is established and articulated through familiarity with foods, but may also be challenged by exposure to disruptive consumption activities. Secondly, how sociability is performed and experienced, including through practices of 'Othering' that emerge through food and drink-centred encounters. Finally, how tourists construct new notions of home through eating and drinking routines. We argue that focusing on these areas helps to understand the intersections of food and drinkrelated practice and tourist experiences in and of place(s).
\end{abstract}

Keywords: drink, eating, experience, food, home and away, place

\section{Introduction}

Tourist experiences are frequently conceptualised as out-of-the-ordinary, contrasting the mundanity of home (Morgan, Lugosi and Ritchie, 2010; Sharpley and Stone, 2012). However, in developing a mobilities conception of travel and being, Larsen, Urry and Axhausen (2006) among others have challenged the traditional dichotomy of extraordinary tourism experiences and mundane experiences of everyday life. Uriely (2005) argued that the divide between extraordinary experiences and the routines of 'ordinary' lives have become blurred, and urged a de-differentiation of tourism. Others, for example, Hui (2008) and White and White (2007) have thus advocated a more fluid conception of tourism which incorporates 
notions of everyday and touristic, as performances of home and away in different places. Furthermore, Cohen and Cohen (2012) and Hannam (2008) suggested that tourism research within the contemporary mobilities paradigm should consider embodied and sensual practices of everyday from an interdisciplinary perspective.

These approaches to examining experiences integrate embodied engagement and non-representable forms of knowledge in tourism (Everett, 2009; Osman, Johns and Lugosi, 2014; Wijaya, King, Nguyen and Morrison, 2013). Specifically food has been identified as an important way to explore emerging forms of consumption, since it enables tourists to internalise experiences through all the senses (Adongo, Anuga and Dayour, 2015; Everett, 2009; Falconer, 2013).

Quan and Wang (2004) proposed a foundational conception of the relationship between food consumption and tourist experiences, differentiating between food as 'supporting consumer experience' and food as 'peak experience'. They argued that the role of food was determined by the intensity and memorability of the consumption experience in relation to daily routines (Quan and Wang, 2004; Tsai, 2016). However, the sharp distinction between supporting and peak experiences of food has been challenged by later studies (e.g. Falconer, 2013; Mkono, Markwell and Wilson, 2013). Osman et al. (2014) advocated a broader conceptualisation, which integrates 'mundane' and 'extraordinary' dimensions of food consumption to understand tourists' experiences. In their study, branded fast food restaurants for some tourists mobilised notions associated with home - i.e. familiarity, predictability and safety, whilst for others they were attractions in their own right. Importantly, venues could shift in meaning during visits, function in dual roles providing 'exotic' and familiarity, and at times be used by tourists to negotiate their broader experiences in unfamiliar places. Osman et al.'s (2014) work thus challenges us to think more broadly about how food, drink and the spaces of hospitality in which they are consumed can be used to negotiate tourists' experiences.

Despite the growing recognition that food-stuffs and eating practices are important components in tourists' experiences (Getz, Robinson, Andersson and Vujicic, 2014; Hay, 2017; Özdemir and Seyitoğlu, 2017), and initial explorations of how food and food-related activities may shape and thus help negotiate tourists' experiences of places (Osman et al., 2014), the intersections of these issues remain under-researched and its dynamics under-conceptualised. In response to this gap in knowledge, this paper draws on Uriely's (2010) framework to explore food experiences as ways to negotiate feelings of home and away in tourism destinations. In doing so this study thus contributes to the growing literature on tourists' experiences in destinations that challenges research to overcome the conceptual divide between tourism and everyday life, as well as understanding the interaction between different forms of travel (Cohen and Cohen, 2012; Hannam, Butler and Paris, 2014; Larsen, 2008; Larsen et al., 2006; Uriely, 2005). More specifically, this study contributes to the growing literature on food experiences in tourism by locating food and drink centrally to understanding tourists' engagement with places, but without reducing foods to either peak or supporting aspects of destination experiences (cf. Falconer, 2013; Getz et al., 2014; Mak, Lumbers and Eves, 2012). In doing so this study helps to conceptualise the intersections of food and tourists' experiences in destination, in particular, how they use food and drink related- 
practices to cope with tensions and maintain control when encountering potentially threatening situations, negotiate inter-cultural relationships, enhance their wellbeing and articulate their identities.

The paper begins by reviewing and synthesising three bodies of literature: first, conceptions of home and away, particularly as it has been used in the tourist experience and Visiting Friends and Relatives (VFR) literature; second, food and tourism experiences in general; and third, embodied experiences of place and food. Following a discussion of the methods, the paper discusses three thematic areas: experiences of situational control and 'comfort food'; experiences of sociability and 'Othering'; and experiences of new homes, constructed through familiarity and routine.

\section{Literature review}

\section{Tourists' experience of away and home}

Much of the tourism literature has suggested that the underlining reason for travelling and visiting destinations resides in the desire to 'experience things' (e.g. Lugosi and Walls, 2013; Morgan et al., 2010; Sharpley and Stone, 2012). Hence, tourist experiences have been conceptualised in contrast to daily routines or normality, differing from people's everyday experiences (Morgan et al., 2010; Ryan, 2002; Sharpley and Stone, 2012; Suvantola, 2002). Holidays signify periods of escape and thus allow tourists to act outside of conventional structures and obligations (Ryan, 2002). Through a temporal change of place, tourists are able to engage in new experiences that are perceived as inaccessible at home (Suvantola, 2002).

However, Hui (2008) suggested that the traditional spatialisation of tourism as the opposition of, and therefore escape from, everyday life limits our understanding of the new mobilities of contemporary tourists. Consequently, Hui (2008) argued that the assumption that tourists are always searching for novel and extraordinary experiences to contrast their home lives is no longer sufficient. New communication technologies have brought elements of travel into everyday life and allowed a 'touristification of home' (Larsen, 2008; Urry, 2002). Through 'imaginative travel', people are also able to experience foreign destinations in front of the TV or the computer at home (Ellegård and Vilhelmson, 2004; Urry, 2002).

Moreover, the 'performative turn' in research has exposed the importance of everyday practices in the context of tourism (Andrews, 2005; Larsen, 2008). This is accompanied by a desire to 'de-exoticise' tourism, acknowledging that tourism practices involve more than an escape from daily routines (Larsen, 2008; Larsen et al., 2006). Instead, in times of increased mobility, various forms of travel emerge as an important part or even constitutive of everyday life (Hannam, 2008; Hannam, Sheller and Urry, 2006). Furthermore, Larsen et al., (2006) suggest that the entanglements of work in tourism, for example through the obligations to various social networks during travel, challenge the conceptualisation of tourism as leisure. They suggest that tourists today are not only escaping but are equally searching for home(s).

These alternative conceptions of tourism are supported by recent studies that consider how tourists' feelings of home and away are increasingly converging (cf. Larsen, 2008; Shani, 2013; White and White, 2007). This emerging body of work 
emphasises how meanings of home go beyond fixed geographical locations to feelings that can be mobilised through routines, specific objects, technologies and significant others (Shani, 2013; White and White, 2007). Discussions of feeling at home in tourism has frequently been discussed in relation to social or 'networking' capital i.e. resources, including technologies, that facilitate mobility and connectivity (Larsen, 2008; Larsen et al., 2006; Shani, 2013; Uriely, 2010; White and White, 2007). In other words, the ability to mobilise social and network capital enable people to access or experience feelings of home in multiple locations. Importantly, however, the notion of home may evoke a sense of comfort but it may also include obligations, for example to other people. Shani (2013) and Uriely (2010) studied the sense of being home while away in the context of VFR tourism. They analysed the implications of social obligations and 'sociability' while visiting friends and relatives, and they problematized a clear-cut differentiation between home and away (Shani, 2013). Hence, it has been argued that elements of extraordinary-ness and everydayness coexist in parts of the tourist experience (Shani, 2013; Hui, 2008).

Uriely (2010), drawing on Schuetz's (1944) notion of the 'stranger', suggested there were three dimensions to tourists' feelings of being home or away: familiarity, situational control, and sociability. Schuetz (1944) defined a stranger as someone who was not acquainted with the norms, systems of knowledge and orientations of the surroundings. Consequently, for Uriely (2010), being home requires familiarity with a place, including specific local knowledge such as social and cultural configurations of behaviours and norms. Familiarity with places may thus be achieved through local hosts, who provide access to local knowledge of 'nontouristic' attractions, such as restaurants, bars and shops (Shani, 2013).

Uriely (2010) also argued that feelings of home could also originate from a sense of privacy and situational control. Goffman's (1959) dramaturgical approach distinguished between the front and back stage of social interactions in everyday life. Accordingly, feelings of home may be created by the ability to control the situation of the front stage and to enjoy full privacy and freedom of social expectations in the back stage (Uriely, 2010). For example, living at the home of local hosts might restrain tourists in their daily habits and routines, and does not provide the possibility for retreat from social obligations in the back stage (Shani, 2013).

Lastly, for Uriely (2010), the sense of home can be associated with social interactions, or 'sociability'. The term was originally introduced by Simmel (1949) to describe interactions between participants of equal social statuses primarily to enjoy each other's company. For Shani (2013), VFR tourism provides opportunities for sociability, but situational inferiorities of tourists in the host-guest relationship may hinder feelings of home.

Uriely's (2010) and Shani's (2013) research focused on VFR tourism. Nevertheless, their underpinning frameworks offer a way to conceptualise tourist experiences through the negotiated experiences of home. Extending this argument, the challenge for the current study was to examine how the socio-material practices of food and drink provision and consumption may shape conceptions of home and away within tourists' experiences of places. In order to do this, the next section reviews existing work considering the relationship between food and tourism experiences. 


\section{Food and tourism experiences}

Food has often been thought of as a secondary product with a supplementary role in the overall tourism experience (Du Rand and Health, 2006; Mak, Lumbers, Eves, and Chang, 2012; Quan and Wang, 2004). However, this has changed and a growing number of destinations now include foods and drinks as key elements in their marketing strategies to achieve competitive advantage (Ab Karim and Chi, 2010; Henderson, 2009; Kesimoğlu, 2015). Therefore, practitioners and academics increasingly conceptualise food consumption as a peak experience for tourists and an important pull factor affecting destination choice (Björk and Kauppinen-Räisänen, 2016; Everett, 2009; Okumus, Okumus and McKercher, 2007). Even though food tourism products may be created to attract niche segments of food tourists, they represent experiences for all tourists (Getz et al., 2014; Henderson, 2009; Williams, Williams and Omar, 2014). Accordingly, tourists' food experiences can adopt diverse forms from eating at restaurants, cafes, street vendors and bars to visits to farms, food festivals or food trails (Ab Karim and Chi, 2010; Falconer, 2013; Getz et al., 2014; Henderson, 2009). This emerging body of work underpins the need to examine further the multiple and often mundane forms of food consumption within tourists experiences of places.

Quan and Wang (2004) distinguished between food as 'peak' touristic experience, when the desire for novelty may be the main motivation for visiting a destination, and food as supporting consumer experience, and thus a mundane, familiar set of practices fulfilling basic consumer needs to realise the main purpose of travel (Osman et al., 2014; Mkono et al., 2013). Both dimensions are interrelated and in certain contexts interchangeable (Therkelsen, 2015; Quan and Wang, 2004). Furthermore, Quan and Wang (2000) suggested that food experiences can contrast, extend or intensify tourists' food-related habits or routines insofar as they desire familiarity and/or novelty in daily life.

It is important to acknowledge that notions of 'novelty' and 'familiarity' are fluid and thus negotiable within tourists' experiences. For example, as Cohen (1972) argued, tourists may generally be pursuing novel experiences through travel; however, they need a certain familiarity or 'environmental bubble' (Cohen, 1972) to engage positively in these new experiences (see also Mak, Lumbers and Eves, 2012). Cohen and Avieli (2004) stated that local food experiences may also be transformed to provide a certain degree of familiarity for tourists. Culinary brokers such as local friends or guides enable tourists to understand, interpret and enjoy local food experiences (Chang, Kivela and Mak, 2011; Cohen and Avieli, 2004). Food and drink as peak and supporting elements, or familiar and unfamiliar practices, may thus (re)emerge in different forms during multiple stages during travel and dwelling in destinations (see e.g. Falconer, 2013; Osman et al., 2014).

In sum, the growing literature has begun to conceptualise the various roles of food and drink within tourist experiences; however, this study seeks to move beyond simplistic distinctions between food as either peak or supporting experience. Food-stuffs and food-related practices in this study are thus viewed as being diffused throughout encounters in and with places. We seek to examine how the socio-material practices of food and drink help to negotiate the experience of places more generally. In order to do this the next section considers conceptions of 
place, examining how existing literature has linked notions of place with food within tourism experiences.

\section{Embodied experiences of place and food}

Although diverse conceptualisations exist, place can be defined as subjective assessments of space though the attribution of personal meaning (cf. Bærenholdt, Haldrup, Larsen and Urry, 2004; Hui, 2008; Meethan, Anderson and Miles, 2006). Hence, places represent more than passive, fixed spatial vessels. Rather, tourists' sense of place is constructed and experienced through individually and collectively negotiated perceptions and interpretations. Moreover, a sense of place can involve nostalgic feelings of past experiences as well as anticipatory place experiences (Suvantola, 2002). Therefore, as a constructed or performed 'entity' involving representations and meanings, place is mobile and subject to negotiation (Hui, 2008).

The body and physical being 'in-place' is fundamental to understanding how places are constructed and experienced (cf. Holliday and Hassard 2001; Somerville and Hartley, 2000; Waskul and Vannini, 2006). The routinized, embodied practices of everyday life come to (re)produce the functions and meanings of places. Within tourist places, bodies receive, mediate and thus transform encounters with the 'other' - whether in the forms of human beings, material objects, sounds, smells, cultural norms or behaviours (Crouch, 2000; Obrador-Pons, 2003; Pritchard, Morgan, Ateljevic and Harris, 2007). Importantly, as Germann Molz (2008) argued, routinized, embodied behaviours may also be part of strategies to negotiate the potential threats of the strange 'other', by invoking the familiarity of home.

The literature on food tourism describes how food-related experiences can be important socio-material, embodied practices providing tourists with a sense of place (Mkono et al., 2013; Tsai, 2016). Food experiences enable strong emotional responses in relation to places (Tsai, 2016). This is relevant because emotions shape experiential outcomes including memorability (Bosangit, Hibbert and McCabe, 2015; Wijaya et al., 2013), and food experiences are able to induce intense, positive emotional responses (cf. Kim Eves and Scarles, 2009).

Food also enables embodied engagement and the generation of nonrepresentable forms of knowledge that differentiates food experiences from other tourist experiences (Adongo et al., 2015; Everett, 2009). Through food, the local culture of a destination can literally be internalised and 'ingestion' thus negotiates cultural and corporeal boundaries (Everett, 2009; Mkono, 2011). Moreover, embodied and multisensory engagement allows tourists to experience a sense of place and a sense of self in place (Morgan et al., 2010). As Tsai (2016) suggested, local foods provide tourists with opportunities to acquire local knowledge, a sense of identification, and belonging to the destination. However, 'bodily involvement' encompasses risks associated with food experiences (Cohen and Avieli, 2004) and tourists may be confronted with symbolic and normative challenges in food encounters (see e.g. Falconer, 2013; Mak, Lumbers and Eves, 2012).

Osman et al. (2014) argued that foodservice spaces in destinations may incorporate the simultaneous or sequential coexistence of food as supporting or peak experience. Eating in branded foodservice venues offered some tourists a temporary sense of familiarity and comfort in between 'extraordinary', physically 
and psychologically intensive, tourism activities. For others, branded foodservice venues, set in local, tourist contexts, were novel attractions in themselves and therefore part of the destination's identity (Osman et al., 2014). The challenge for the current study is to develop this line of enquiry further by examining how food and drink-related embodied experiences facilitate or mobilise feelings of home and away while travelling, thus helping tourists negotiate spaces and thus experiences of places.

\section{Methodology}

\section{Approach, sampling and data collection}

In line with recent studies of tourists emphasising subjective dimensions of experience, this study adopted an interpretivist approach that understands the world as socially constructed and subject to the interpretations of different social actors (cf. Banyai and Glover, 2012; Bosangit et al., 2015; Mkono et al., 2013; Mura, 2015). Social reality is perceived as multiple, contradictory and interconnected, and the researcher's objective is to gain insight into tourists' perspectives on the world.

Travel bloggers were identified as 'key [information] streams' (Lugosi et al., 2012): as people on the move, the travel bloggers represented 'information-rich cases' (Patton, 2015) to investigate tourists' food and drink-related experiences. More specifically, blog analysis can provide personalised, informant-driven insights into experiences in and across multiple destinations and consumption places (cf. Ji, Li and Hsu, 2016; Magnini, Crotts and Zehrer, 2011; Wang, Weaver and Kwek, 2016; Wu and Pearce, 2016). This type of data facilitates the study of symbolic, contextual and subjective information from tourists' perspectives, helping to appreciate personal meaning-making (Bosangit et al., 2015; Van Nuenen, 2016; Wang and Alasuutari, 2017).

To capitalise on the distinctive nature of data available through blogs, a purposive, criterion-driven, multi-step sampling strategy was adopted (cf. Kozinets, 2015; Lugosi, Janta and Watson, 2012; Patton, 2015). Sampling, data collection and analysis activities thus overlapped. Specifically, in line with interpretivist, internetbased qualitative studies, this involved reviewing blogs' contents, continually questioning how it communicated food and drink related experiences in tourist settings. This ongoing process of data collection and analysis subsequently guided decisions to focus on a specific sample of blogs and bloggers over others.

Following Kozinets' (2015, 168-169), the general principles of 'data richness' and 'relevance to the study's focus' were key criteria determining appropriateness. In practice, drawing on existing studies, the primary set of criteria used to reduce the data and refine the sample for subsequent analysis were as follows:

- Blog contains some posts on food, but food not a general theme of the blog.

This helped to identify travel and destination-specific issues.

- Richness of data (number of posts, variety of posts, depth of posts, additional context) (Kozinets, 2015).

- Connection with other social media sites to identify 'key streams' (Lugosi, Janta and Watson, 2012) or 'market leaders' (Wu and Pearce, 2014).

- Personal narratives in the blog, which helped to better understand the bloggers, including their characters, values, norms and backgrounds. 
- Minimal 'noise' (i.e. advertisement, obvious product placements) (Carson, 2008).

- Personal perspective of posts to avoid dry-content (Carson, 2008) and commercial interests (Volo, 2010).

- Variety of destinations to show commitment and interest (Bosangit, Hibbert and McCabe, 2015).

Secondary criteria were also defined to ensure the practicability of data to conduct a time-efficient analysis of contemporary blog content (Palinkas et al., 2015):

- Blog up-to-date and at least online since 2014.

- Date of publication available for individual blog entries.

- English language.

- Possibility to navigate the site effectively (search function, subcategories of posts).

Similarly to Li and Wang (2011) and Law and Cheung (2010), Google.com with its integrated PageRank system was initially used to search for key words: 'travel blog(s)' and 'travel blogger(s)' in order to identify the voices of 'market leaders' - i.e. bloggers (and sites) that generate higher internet traffic and thus have a greater following (Wu and Pearce, 2014). The resulting blogs were reviewed from the top of the ranking (cf. Law and Cheung, 2010). However, since the most highly ranked travel blogs were commercial in nature and involved an unmanageable amount of 'noise', in line with other studies, other search engines were also used to generate more appropriate results (cf. Carson, 2008; Volo, 2010). They included Yahoo.com and the more specific blog search engine Regator.com, where all blogs listed under the category 'travel' were evaluated. During the research process, across the three search sources, 128 blogs were evaluated according the criteria outlined above for their coverage of food and drink related activities. After the initial round of analysis, the most suitable 20 travel blogs were scrutinised further to reduce the number to be used in subsequent detailed analysis. At this stage an exploratory review of two blogs was conducted to evaluate their relevance. Consequently, both were excluded from the final sample because the writers did not provide enough data about themselves in the narratives. Moreover, this stage of the overall exploratory review and sampling process helped to redefine the selection criteria and identify the final sample. Three travel blogs were selected that provided the richest insights into personal food experiences. The bloggers are referred to with the pseudonyms: Lucy and John (a travelling couple), Melanie and Tom.

The rationale for focusing on these bloggers was not driven by (post-)positivist assumptions and a calculative logic which claims 'representativeness' on the basis of a numerically determined sample of a food/travel blogger population. Nor was our study built on realist ontologies, assuming a finiteness of meaning in a data set, reflected in 'saturation' in analysis (cf. Ji et al., 2016). Rather, working in an interpretivist tradition, we focused on examining the qualities of the data to decide their appropriateness for exploring conceptual issues. Importantly, this rejects the assumption that a particular configuration of data or analysis represents the only and exhaustive way to interpret human experiences. 
In the subsequent sampling stage, relevant posts were selected from the three travel blogs to be downloaded for further analysis (cf. Kozinets, 2015; Wu and Pearce, 2014). The initial data collected for analysis also included other usergenerated content, such as images, comments and links; however, the discussion here focuses on the textual analysis. The blog entries that included food experiences in relation to a destination and were narrated from a personal perspective, were classified as 'on-topic' and 'informational' (see Kozinets, 2015) and therefore included in subsequent analysis. Other posts that were not relevant to the research question were eliminated from the data set. Table 1 provides an overview of the data.

\begin{tabular}{|l|l|l|l|l|l|l|}
\hline Blog & Countries & $\begin{array}{l}\text { Time- } \\
\text { span }\end{array}$ & $\begin{array}{l}\text { Blog } \\
\text { Entries }\end{array}$ & Words & Images & Comments \\
\hline $\begin{array}{l}\text { Lucy and } \\
\text { John }\end{array}$ & 16 & $\begin{array}{l}2014- \\
2016\end{array}$ & 127 & $129^{\prime} 194$ & 182 & 340 \\
\hline Melanie & 12 & $\begin{array}{l}2013- \\
2016\end{array}$ & 116 & $116^{\prime} 606$ & 337 & 282 \\
\hline Tom & 16 & $\begin{array}{l}2013- \\
2016\end{array}$ & 67 & $105^{\prime} 128$ & 195 & 1020 \\
\hline \hline Total & - & - & 310 & $350^{\prime} 928$ & 714 & 1642 \\
\hline
\end{tabular}

Table 1: Frequencies and Data Size of Individual Blogs and in Total

\section{Data analysis}

The study adopted a principally atheoretical, thematic approach to analysis (Braun and Clarke, 2006). Nevertheless, similarly to Mura (2015), aspects of narrative analysis were integrated within thematic analysis. The contextualisation of the narrator's identity and the mobilities between various destinations were key for the understanding of the overall experiences in relation to the research aim (Banyai and Glover, 2012). The chronological story, deeper meanings assigned upon the experience by the author, the identification of pivotal events and the (re)creation of identities were examined in their narratives (cf. Bosangit et al., 2015; Banyai and Glover, 2012).

The thematic analysis was conducted according to the six phases proposed by Braun and Clarke (2006). Analysis began with familiarisation with the data early in the research process during the multi-step sample selection process. In the second phase, a coding framework was developed to reorder the data into distinct thematic groups. The coding themes were influenced by the literature and the data. Data were coded manually by highlighting text units. The length of each unit varied from a subset of a sentence up to a paragraph. At the third stage, the different text segments were carefully read in order to identify broader themes and subthemes.

Fourthly, the abstracted themes were ordered into higher order themes. During this phase, some coding categories were eliminated, but it was also at this stage that a key latent theme emerged: the tourists' experience of food appeared as 
negotiations of feelings regarding home and away. Consequently, following engagement with Uriely's (2010) work, the fifth stage involved the review and reordering of data in line with his framework for understanding tourists' conceptions of home and away. These were used to structure the construction of the findings in the sixth stage of analysis (Braun and Clarke, 2006): the construction of the findings and discussion for the manuscript.

\section{Findings and discussion}

\section{Experiences of situational control and 'comfort food'}

Many of the entries described eating experiences involving familiar foods and 'comfort foods' (i.e. recognisable and thus 'safe' foods, which were often unhealthy, but stimulated an instant sense of pleasure). Accessing and eating such foods enabled travellers to (re)claim a sense of situational control in otherwise strange and unfamiliar places. Similarly, familiar restaurants, serving globally-available cuisines, enabled the bloggers to be at ease with the environment, effectively negotiating the feeling of being a tourist or 'stranger' (Schuetz, 1944) since the cultural codes and rules surrounding the food related practices were known (cf. Shani, 2013; Uriely, 2010). For example, Lucy and John's experiences of eating at Western 'gringo' restaurants during their travels were described as welcoming changes allowing them to feel at home. However, they did not necessarily conceive the foodservice spaces reductively as 'environmental bubbles' (Cohen, 1972) that facilitated situational control through excluding the strange gastronomy of destination. Rather, they suggested that they were novel, emotionally-laden food experiences worthwhile in their own right. Nevertheless, describing a patisserie in Oaxaca, they recalled how enjoyable feelings in daily routines at home were used to interpret and value food experiences within the tourism context:

Everybody loves a sticky bun. Few things are more comforting than a morning spent in bed with a proper cup of tea, the newspaper and some fresh pastries. Get the really fancy cakes, make it a broadsheet and you can even call this a 'cultured event'.

Lucy and John returned several times to the establishment to indulge in sweets that they remembered from home. The familiar taste that differentiated the pastry from the local fare made this food experience memorable for them. The importance of flavour to positively experience food was also reported by Chang et al. (2011). They found that unfamiliar tastes can hinder positive encounters with indigenous foods due to lack of knowledge and ability to judge the quality of the food. Hence, additionally to the hedonistic pleasures experienced through familiar food, it is also suggested that the bloggers' wider knowledge enabled a better understanding of the quality of the food or the foodservice venue (cf. Chang et al., 2011). Moreover, similarly to the food bloggers in Lugosi et al.'s (2012) study, the expertise performed through the narration of their food experiences was part of a strategy to legitimise their restaurant recommendations to their readers (see also Lugosi, 2016). 
In other entries, travel bloggers described how limited food options restricted them from feeling at ease and thus made them aware of the differences between home and away. They described how their food habits and daily routines were threatened in certain destinations, or more generally while travelling. Limited situational control over the habitual diet could negatively affect the traveller's ability to feel at home, particularly when it potentially compromised their health. As Germann Molz (2007) suggested, food restrictions were linked to embodied experiences of their own physical vulnerability (see also Falconer, 2013). For example, Melanie described problems such as stomach pain, which she attributed to her eating habits while travelling. She explains:

My very worst experience with my eczema was this past year. I was on a ten-day press trip through Louisiana where I ate lots of food that wasn't a part of my diet and slept little.

She experienced a lack of daily routine and unknown foods as threats to her wellbeing. Consequently, she controlled her food consumption to maintain a feeling of security and predictability similarly to that experienced at home.

Similarly to Falconer's (2013) respondents, the travel bloggers mentioned numerous concerns about negative effects of food intake in destinations. They expressed health issues stemming from adopting unhealthy lifestyles while travelling or cravings for unhealthy foods. On the one hand, the possibility to continue with 'normal' food-related routines in destinations facilitated a feeling of home through situational control (Uriely, 2010). On the other hand, some food experiences appeared as positively memorable especially because they diverged from habitual diets and stressed perceptions of feeling away. Similarly to Therkelsen (2015), the bloggers described some degree of openness - a willingness to break with diets and indulge in otherwise unhealthy food. This was especially evident with Lucy and John, for whom feelings of home and away were often negotiated through food-related restriction and indulgence.

However, indulgence as liberation from daily routine did not necessarily mean a feeling of away in the sense of experiencing local food: it was often connected with familiarity. Situational control was manifested in the consumption of unhealthy 'comfort food' that was not part of the ordinary diet but strongly reminded the bloggers of home or another familiar place that they were referencing in their practices. 'Comfort food' referred to different foodstuffs for different travellers, but as a category or genre of food it emerged repeatedly in the bloggers' narratives. Moreover, it did not necessarily have to be the food of their current home and thus points of return for the travel bloggers. As Ellegarrd and Vilhelmson (2004) argued, the notion of home was a fluid, mobile concept. For example, Tom rarely mentioned German food, even though he was living in Berlin. His unhealthy food cravings were connected with Texan food, especially TexMex, a common cuisine of the place of his upbringing. The bloggers identified alternating feelings of home, which often invoked multiple homes rather than referencing a single one (cf. Hui, 2008). Moreover, the data suggested that feelings of home induced by 'comfort food' were not necessarily experienced as a tactic to mobilise familiarity in an unknown environment, as reflected in Osman et al. (2014). Rather, in the travel context, such 
food was experienced as out-of-the-ordinary due to nostalgic feelings of home or the enjoyment of preferred and familiar flavours that were associated with home.

\section{Experiences of sociability and 'othering'}

The bloggers narrated how food experiences facilitated positive and memorable sociability. Echoing themes in previous studies, social bonding was an important factor influencing food experiences during travel (cf. Heimtun, 2010; Therkelsen, 2015; Wijaya et al., 2013). However, sociability as an ideal form of interaction between equal participants (cf. Simmel, 1949; Uriely, 2010) was rarely achieved in relations with local people. The travel bloggers became aware of differences between them and 'Others' during food-related social interactions. Analogously to Shani's (2013) accounts of interactions in tourism contexts, at times the bloggers described situational inferiority due to a lack of local knowledge. For example, Lucy and John described the local people at a Columbian market and how they felt among them:

People seemed genuinely happy to have us there, exploring their heritage and their livelihoods, with only the odd look of bewilderment as we took the 20th photo of the same fruit.

Lucy and John felt that their noticeably 'foreign' behaviour at the marketplace was not taken in a negative way, but interpreted as demonstrating interest in local culture. Their account suggested a perception of mutual appreciation between them and the local people through the experience. Nevertheless, their narrative also highlighted distance between them and the 'Others', characterised by the 'tourist gaze' (Urry and Larsen, 2012), and situational inequality (Shani, 2013). Hence, food encounters that 'fail' the concept of sociability induced feelings of being away and were often characterised by processes of 'Othering' - insofar as cultures were appraised through Western-centric value systems and power relations (cf. Mkono, 2011).

Food experiences could also induce feelings of home through social interactions with travel companions, friends and working colleagues. In line with Therkelsen's (2015) findings, the travel bloggers engaged in food experiences as means of social bonding. Lucy and John described positive, memorable food experiences consisting of spending time with each other, which strengthened their personal relationship. Similarly, Melanie often met old friends or bonded with other bloggers through shared eating and drinking experiences in destinations. Melanie and Tom's narratives on travel also provided examples of increased travel due to social obligations, as described by Larsen et al. (2006). The bloggers described how they enhanced their social capital by meeting friends over shared meals and partook in food events that appeared to support their identity as travel bloggers. Reflecting the networked characteristics of sociability in the contemporary mobilities paradigm (Hannam et al., 2006; Larsen et al., 2006), for Melanie and Tom, building productive relationships through food experiences represented an important motivation to visit destinations. 


\section{Experiences of new homes: familiarity and routine}

Travel bloggers attached meanings associated with home to various places within destinations. Importantly, memories of home were related to familiar foods or cuisines of more than their current homes or points of return. The experience of certain foods enabled the food bloggers to recall different places familiar to them. Such places included former hometowns, temporary homes in foreign destinations or even imagined places experienced through ethnic restaurants at home. The travel blogs revealed that food experiences could induce memories and cravings for the local food of a place that is far away. For example, Thai food on Tom's and Melanie's blogs or Mexican food on Lucy and John's posts were recurring themes and connected to strong positive memories. As discussed earlier, they used multisensory descriptions to portray the cuisines they missed or the local specialities of a destination. Moreover, such nostalgic feelings of home turned up long-after their visit.

Hence, it can be argued that increased familiarity with local foods may lead to emotional connections to a place. The more familiar the food of a destination became the more personal and meaningful the experience of the food was for the bloggers. Accordingly, the once novel foods that originally induced feelings of away could turn into an experience of home. As Chang et al. (2011) suggested, knowledge of local food enables tourists to appreciate the experiences beyond their own cultural framework. This can be observed on Lucy and John's travel blog, where they collected a wide-range of experiences of local specialities of Latin America. By the end of their trip they used a more refined language to judge their experiences of the local speciality 'empanada' because they gained familiarity with the dish over time. Accordingly, they described positive memorable experiences of restaurants and recommended specific places with references to local foods like empanadas that they had become accustomed to.

Moreover, familiarity connected the travellers emotionally with the place and led to nostalgic feelings of home once back in their old environment. Lucy and John recall idyllic pictures of Mexican food:

Forget everything you think about Mexican food: it's not fajitas, it's not burritos and it doesn't come out of yellow box. On every street you'll find a stall with home-made salsas, hand-made tortillas, frijoles of some variety, fresh coriander and sizzling meat waiting to be layered, wrapped and wolfed down.

Increased local knowledge, familiarity and therefore higher appreciation of local food experiences were also recognizable on the other travel blogs. Overall, the pivotal role of traditional food tourism attractions in subsequent experiences of local foods became apparent. Both Tom and Melanie adopted restaurant recommendations, opinions and anecdotes from food tours in their own blog narratives. Similarly to Lucy and John's changing descriptions of empanadas, the descriptions of local foods after food tourism experiences became more detailed and personal. Importantly, their experiences of feelings of home were due to gaining knowledge from locals that was normally only accessible to 'cultural insiders'. Shani (2013) similarly explained how local hosts enabled tourists to feel notions of home 
through sharing their local expertise that facilitated 'non-touristic' experiences of everyday life at destinations.

It could be argued that travellers' experiences of feelings of home through food-based encounters did not just connect them with places by providing them an 'environmental bubble' (Cohen, 1972). Through achieving familiarity with local food options or cuisines, they attached personal meanings of home that could even result in nostalgic recollections after the trip. The travel bloggers became familiar with local foods over time; or, alternatively, external guidance concerning food tourism experiences, obtained for example through local advice or textual reviews, transmitted local knowledge. This observation extends Tsai's (2016) findings that memorable experiences of local food positively influenced their place-attachment and behavioural intentions because they satisfied tourists' need for exciting and novel experiences. At first, the travel bloggers recalled their memorable experiences of 'strange' or unfamiliar foods to their audience (cf. Adongo et al., 2015). However, increased familiarity with foodstuffs and foodways appeared to enhance their feelings of being at home at a destination. They attached personal meanings and created memories of a new home. In such cases, travel bloggers expressed nostalgic recollections of destinations and positive behavioural intentions in order to retrieve familiar food experiences.

The travel bloggers also displayed intentions to create feelings of home through establishing daily routines and seeking to assure moments of privacy. They sought to recreate notions of familiarity by returning to the same restaurant during every visit to a destination. All the bloggers mentioned routines of travel that provided them with similar feelings of being 'at-home' in different destinations. For example, they described how they enjoyed drinking beer at the beach or sitting in a coffee shop of a busy city. Although the place itself might not have been familiar to them, the well-known ritual allowed them to display 'situational control' (Shani, 2013). One could argue that such rituals help tourists achieve an 'ontological comfort of home' (Quan and Wang, 2004), allowing them to subsequently engage in more novel tourist experiences (Mak, Lumbers and Eves, 2012). However, an alternative interpretation is that such food and drink consumption connected travellers with places in ways that made them feel at home. The feeling of control disguised their unfamiliarity with the place and allowed them to not stand out as a tourist. They narrated how they experienced the place as a 'quasi'-local, which allowed them to just 'be' in the place. For example, Tom described eating lunch at a sandwich shop in Rome as a key event in his visit:

Sitting by the fountain in Piazza della Madonna dei Monti with my sandwich and an Italian soda from Full Monti, I finally realized the real beauty of Rome.

Tom's refection is not necessarily concerned with a novel or 'touristic' experience. Rather, it is possible to argue that the food-based experience allowed him to distance himself from the 'tourist gaze' (Urry and Larsen, 2012), and to enjoy an alternative, more 'real', sense of place by being enlightened or informed analogously to an cultural 'insider'. Similarly, all the bloggers described feelings of 'true' connections with the places by just 'being' there. Habitual food experiences 
involving low or no bodily risks allowed them to perform 'ordinary life', inducing feelings of home in a foreign place. Moreover, it allowed them to attain some privacy in public, because they did not feel they were perceived by others as strangers through conspicuous tourist behaviours. They established new feelings of home in destinations through food-based routines that blurred their visible displays of tourist identities.

\section{Conclusion}

This study examined the intersections of tourists' food-related practices and their negotiations of destination experiences. By doing so it contributes to knowledge in several ways. The findings provide consumer-driven insights into tourists' personal meaning-making and subjective experiences of food and place (Bosangit et al., 2015). More specifically, much of the contemporary research on local food and food tourism experiences stresses their extraordinary dimensions (Adongo et al., 2015; Everett, 2009; Williams et al., 2014). In sum, it is often argued that travel to new places provides opportunities to engage in novel food experiences. In contrast, our analysis highlighted how notions of home and familiarity may also emerge as important dimensions in tourists' food-related experiences. Existing research has suggested that familiar food experiences are sought after by tourists to provide them with safe spaces from which they could explore other tourist experiences (cf. Mak, Lumbers and Eves, 2012; Osman et al., 2014). However, our data suggest that feelings of familiarity and the assignment of the qualities of home can be negotiated situationally. In particular moments during travel, foodstuffs and food-related routines can create meaningful and emotionally enriching experiences as tourists occupy, appropriate and internalise places, enfolding them into their own biographies. Places (re)appropriated through food and drink-related practices may be used to facilitate social connectivity and articulate belonging to imagined or real social groups. These may encompass relationships with residents or other mobile individuals. The data thus stresses the need to research further how tourists assign meanings and perform the fluid qualities of places through their consumption of food and drink.

Familiar foods and drinks can provide what may be called 'small-peak' experiences: ones with novel properties but not representing radical, extraordinary qualities. For example, the consumption of familiar or comfort foods may be treated as novelties because they are accessible in a 'foreign' place; mundane foods of a tourist destination may also be made familiar as part of new, place-specific rituals. Importantly, the same foodstuffs or consumption contexts i.e. foodservice outlets may acquire new meanings at different points during the same trip or have alternative social and psychological functions in other destinations.

The data also highlighted how the shifting, situationally-defined roles of foods and food-related activities may also work against tourists' interests and wellbeing, particularly if notions of home and familiarity were perceived to be compromised. This could be due to the lack of access to foods at points during travel or because encounters with unfamiliar foods, foodscapes and rituals reinforced outsider status or social distinctions. This further reinforces the potential benefits of exploring in future research how other travellers, in other destinations, may use food and drink 
to negotiate notions of home and familiarity. Moreover, future research could go further in acknowledging the agency of foods and the power of associated practices to transform tourists' conceptions of home and familiarity.

Following on from the previous set of points, the findings also contribute to the growing literature on food experiences and emerging forms of alternative tourist experiences (Osman et al., 2014; Quan and Wang, 2004). In line with other studies, the findings indicate how foods and drinks facilitate embodied, multisensory experiences of places (Everett, 2009). The narratives of food and drink-related experiences appearing in travel bloggers' descriptions of destinations reveal personal and emotional connections with the places they visited (Tsai, 2016). Hence, the data reinforces the growing literature stressing the value of local cuisines for differentiating destinations and enhancing memorable experiences (Adongo et al., 2015; Okumus et al., 2007). However, the data also stresses that it is not simply the foodstuffs that matter; rather, the contextual experiences involved in their production and consumption, which encompasses social and material factors, create meaningful encounters with places. More importantly, given the complex and potentially shifting interactions between food, place and experience, future research should avoid oversimplifying categorizations of foods as strange/familiar, or the tourists who consume them as being novelty seekers/conservatives. Rather it is the situational use and place-specific, subjective experiences that may shape how tourists assign such values to foods, to the places where they are consumed, and to their own practices. It has been argued that the spaces of food, drink and hospitality consumption can promote unique interactions and the formation of distinct cultural practices (Harrison and Lugosi, 2013). Therefore, this study invites further contextsensitive studies of unique and subjectively-interpreted food, drink and hospitality experiences to understand how they interact with, entrench or potentially transform tourists' identities.

Finally, the findings stress how new forms of mobile lifestyles might be reflected in tourists' food and drink experiences. In line with Uriely's (2005) decontextualisation of tourism, it can be argued that food-related practices can induce multiple feelings of home and away while being away. Food and drink experiences provide opportunities for tourists to feel at home at a destination. Hence, this study highlights how tourists may connect with places through more fluid conceptions of home and away (cf. Hui, 2008; Shani, 2013; Uriely, 2010). The data show how practices of everyday life can potentially be examined to expand existing literature on tourism mobilities focusing on accommodation, hospitality, leisure or specific types of niche tourism activity (see e.g. Andrews, 2005; Shani, 2013; Uriely, 2010; White and White, 2007). Eating and drinking are universal practices and clearly offer scope to conduct cross-cultural studies of how people engage in them to negotiate place(s). However, there are numerous other commonly performed but mundane forms of behaviour, for example walking, talking, reading, using technologies or other everyday objects that may also be examined to better understand how people negotiate feelings of home and away in increasing mobile lives more generally (cf. Shani, 2013; Uriely, 2010). Following Hui (2008), such research could help to better understand the de-contextualisation of tourism by disrupting a narrow spatialisation of it, thus opening tourism studies to see the everyday and the touristic - or aspects of home and away - in all forms of mobilities. 


\section{Blogger Vignettes}

The first travel blog was written by a couple from London, UK: Lucy and John, who were estimated to be around 30 years of age at the time of writing their blog. They first started the blog to document their travel adventures through Latin America. They described themselves as 'budget backpackers, slow travellers and foodies'. While travelling the blog became increasingly important and they now describe themselves as professional bloggers. The data includes 127 posts from 2014 to 2016 on food experiences in 15 different countries in South America (and one entry from the UK). The average post was over 700 words long and included around 3 comments and more than one image.

The second travel blog was created by Melanie, from Atlanta, USA. Melanie was in her late 20s and chose to live a 'life of perpetual travel'. As a freelance writer, she published other articles and maintained a second blog, beside the travel blog under analysis. She spent extended periods traveling in Australia, Thailand and Cambodia. She lived at her parents' house, when she was not on the road. Her food experiences often talked about her anxiety and health issues that she attempted to control through her diet. However, she described how travel and eating unknown food had changed her life positively. The downloaded data includes 116 blog entries from 2013 until 2016. The average post was over 1000 words long and included more than 2 comments and around 3 images.

The third blog was written by Tom from Texas, USA who moved to Berlin, Germany after a year travelling. He is estimated to be between 25 and 30 years of age. Tom described himself as a 'gay hipster' and stated that he seeks to write as a fulltime travel blogger for a male audience. Now living in Berlin, his blog entries on food experiences are mostly part of narratives of short trips to other European cities, travels to the US and memories from the year on the road, predominantly Thailand. The downloaded data comprised of 67 posts from 2013 to 2016 about experiences in 16 different counties. The average blog entry was over 1500 words long and included over 15 comments and around 3 images. The data relating to Tom's online activities also included 4 videos and a radio interview.

\section{References}

Ab Karim, S. and C. G.-Q. Chi (2010) 'Culinary Tourism as a Destination Attraction: An Empirical Examination of Destinations' Food Image', Journal of Hospitality Marketing \& Management 19: 531-55.

Adongo, Ch. A., S. W. Anuga and F. Dayour (2015) 'Will They Tell Others to Taste? International Tourists' Experience of Ghanaian Cuisines', Tourism Management Perspectives 15: 57-64.

Andrews, H. (2005) 'Feeling at Home: Embodying Britishness in a Spanish Charter Tourist Resort', Tourist Studies 5(3): 247-66.

Banyai, M. and T. D. Glover (2012) 'Evaluating Research Methods on Travel Blogs', Journal of Travel Research 51(3): 267-77. 
Björk, P. and H. Kauppinen-Räisänen (2016) 'Exploring the Multidimensionality of Travellers' Culinary-Gastronomic Experiences', Current Issues in Tourism 19(12): 1260-80.

Bosangit, C., S. Hibbert and S. McCabe (2015) 'If I Was Going to Die I Should at Least be Having Fun: Travel Blogs, Meaning and Tourist Experience', Annals of Tourism Research 55: 1-14.

Bærenholdt, J.O., M. Haldrup, J. Larsen and J. Urry (2004) Performing Tourist Places. Aldershot: Ashgate.

Braun, V. and V. Clarke (2006) 'Using Thematic Analysis in Psychology', Qualitative Research in Psychology 3(2): 77-101.

Carson, D. (2008) 'The 'Blogoshpere' as a Market Research Tool for Tourism Destinations: A Case Study of Australia's Northern Territory', Journal of Vacation Marketing 14: 111-19.

Crouch, D. (2000) 'Places around us: Embodied lay geographies in leisure and tourism', Leisure Studies 19(2): 63-76.

Chang, R. C. J., J. Kivela and A. H. N. Mak (2011) 'Attributes That Influence the Evaluation of Travel Dining Experience: When East Meets West', Tourism Management 32(2): 307-16.

Cohen, E. (1972) 'Toward a Sociology of International Tourism', Social Research 39(1): 164-89.

Cohen, E. and N. Avieli (2004) 'Food in Tourism: Attraction and Impediment', Annals of Tourism Research 31(4): 755-78.

Cohen, E. and S. A. Cohen (2012) 'Current Sociological Theories and Issues in Tourism', Annals of Tourism Research 39(4): 2177-202.

Du Rand, G. E. and E. Heath (2006) 'Towards a Framework for Food Tourism as an Element of Destination Marketing', Current Issues in Tourism 9(3): 206-34.

Ellegård, K. and B. Vilhelmson, B. (2004) 'Home as a Pocket of Local Order: Everyday Activities and the Friction of Distance', Geografiska Annaler: Series B, Human Geography 86(4): 281-96.

Everett, S. (2009) 'Beyond the Visual Gaze? The Pursuit of an Embodied Experience Through Food Tourism', Tourist Studies 8(3): 337-58.

Falconer, E. (2013) 'Transformations of the Backpacking Food Tourist: Emotions and Conflicts', Tourist Studies 13(1): 21-35.

Germann Molz, J. (2007) 'Eating Difference: The Cosmopolitan Mobilities of Culinary Tourism', Space and Culture 10(1): 77-93.

Germann Molz, J. (2008) 'Global abode: Home and mobility in narratives of roundthe-world travel', Space and Culture 11(4): 325-342.

Getz, D., R.N.S. Robinson, T.D. Andersson and S. Vujicic (2014) Foodies and Food Tourism. Oxford: Goodfellow Publishers.

Goffman, E. (1959) The Presentation of Self in Everyday Life. New York: Anchor Books.

Hannam, K. (2008) 'Tourism Geographies, Tourist Studies and the Turn Towards Mobilities', Geography Compass 2(1): 127-39.

Hannam, K., G. Butler and C.M. Paris (2014) 'Developments and Key Issues in Tourism Mobilities', Annals of Tourism Research 44: 171-85.

Hannam, K., M. Sheller and J. Urry (2006) 'Editorial: Mobilities, Immobilities and Moorings, Mobilities', Mobilities 1(1): 1-22. 
Harrison, D. and P. Lugosi (2013) 'Tourism Culture(s): The Hospitality Dimension', Tourism Recreation Research 38(3): 269-279.

Holliday, R. and J. Hassard (eds.) (2001) Contested Bodies. London: Routledge.

Hay, B. (2017) 'Missing Voices: Australian Children's Insights and Perceptions of Family Holidays', Hospitality and Society 7(2): 133-155.

Heimtun, B. (2010) 'The Holiday Meal: Eating Out Alone and Mobile Emotional Geographies', Leisure Studies 29(2): 175-92.

Henderson, J. C. (2009) 'Food Tourism Reviewed', British Food Journal 111(4): 31726.

Hui, A. (2008) 'Many Homes for Tourism: Re-Considering Spatializations of Home and Away in Tourism Mobilities', Tourist Studies 8(3): 291-11.

Ji, M., M. Li and C. H. Hsu (2016) 'Emotional Encounters of Chinese Tourists to Japan', Journal of Travel \& Tourism Marketing 33(5): 645-57.

Kesimoğlu, A. (2015) 'A Reconceptualization of Gastronomy as Relational and Reflexive', Hospitality and Society 5(1): 71-91.

Kim, Y.G., A. Eves and C. Scarles (2009) 'Building a Model of Local Food Consumption on Trips and Holidays: A Grounded Theory Approach', International Journal of Hospitality Management 28: 423-31.

Kivela, J. and J.C. Crotts (2009) 'Understanding Travelers' Experiences of Gastronomy through Etymology and Narration', Journal of Hospitality \& Tourism Research 33(2): 161-92.

Kozinets, R.V. (2015) Netnography Redefined. London: Sage.

Larsen, J. (2008) 'De-Exoticizing Tourist Travel: Everyday Life and Sociality on the Move', Leisure Studies 27(1): 21-34.

Larsen, J., J. Urry and K.W. Axhausen (2006) 'Networks and Tourism: Mobile Social Life', Annals of Tourism Research 34(1): 244-62.

Law, R. and S. Cheung (2010) 'The Perceived Destination Image of Hong Kong as Revealed in the Travel Blogs of Mainland Chinese Tourists', International Journal of Hospitality \& Tourism Administration 11: 303-27.

$\mathrm{Li}, \mathrm{X}$. and Y. Wang (2011) 'China in the Eyes of Western Travelers as Represented in Travel Blogs', Journal of Travel \& Tourism Marketing 28: 689-719.

Lugosi, P. (2016) 'Socio-technological authentication', Annals of Tourism Research 58: 100-13.

Lugosi, P., H. Janta and P. Watson (2012) 'Investigative Management and Consumer Research on the Internet', International Journal of Contemporary Hospitality Management 24(6): 838-54.

Lugosi, P. and A. Walls (2013) 'Researching Destination Experiences: Themes, perspectives and challenges', Journal of Destination Marketing and Management 2(2): 51-8.

Magnini, V.P., J.C. Crotts and A. Zehrer (2011) 'Understanding Customer Delight: An Application of Travel Blog Analysis', Journal of Travel Research 50(5): 535-45.

Mak, A.H.N., M. Lumbers and A. Eves (2012) 'Globalisation and Food Consumption in Tourism', Annals of Tourism Research 39(1): 171-96.

Mak, A.H.N., M. Lumbers, A. Eves and R.C.Y. Chang (2012) 'Factors Influencing Tourist Food Consumption', International Journal of Hospitality Management 31: 928-36. 
Meethan, K., A. Anderson and S. Miles (eds) (2006) Tourism, Consumption and Representation: Narratives of Place and Self. Wallingford: CABI International.

Mkono, M. (2011) 'The Othering of Food in Touristic Eatertainment: A Netnography', Tourist Studies 11(3): 253-70.

Mkono, M., K. Markwell and E. Wilson (2013) 'Applying Quan and Wang's Structural Model of the Tourist Experience: A Zimbabwean Netnography of Food Tourism', Tourism Management Perspectives 5: 68-74.

Morgan, M., P. Lugosi and J.R.B. Ritchie (eds) (2010) The Tourism and Leisure Experience: Consumer and Managerial Perspectives. Bristol: Channel View.

Mura, P. (2015) 'Perceptions of Authenticity in a Malaysian Homestay: A Narrative Analysis', Tourism Management 51: 225-33.

Obrador-Pons, O.P. (2003) 'Being on holiday: Tourist dwelling, bodies and places', Tourist Studies 3(1): 47-66.

Okumus, B., F. Okumus and B. McKercher (2007) 'Incorporating Local and International Cuisines in the Marketing of Tourism Destinations: The Cases of Hong Kong and Turkey', Tourism Management 28: 253-61.

Osman, H., N. Johns and P. Lugosi (2014) 'Commercial Hospitality in Destination Experiences: McDonald's and Tourists' Consumption of Space', Tourism Management 42: 238-47.

Özdemir, B. and F. Seyitoğlu (2017) 'A conceptual study of gastronomical quests of tourists: Authenticity or safety and comfort?', Tourism Management Perspectives 23: 1-7.

Patton, M.Q. (2015) Qualitative Research and Evaluation Methods. 4th edn. Thousand Oaks, CA: Sage.

Pritchard, A., N. Morgan, I. Ateljevic and C. Harris, C. (eds.) (2007). Tourism and gender: Embodiment, Sensuality and Experience. Wallingford: CABI.

Quan, S. and N. Wang (2004) 'Towards a Structural Model of the Tourist Experience: An Illustration from Food Experiences in Tourism', Tourism Management 25: 297-305.

Ryan, C. (ed.) (2002) The Tourist Experience. 2nd edn. London: Continuum.

Schuetz, A. (1944) 'The Stranger: An Essay on Social Psychology', American Journal of Sociology 49(6): 499-507.

Shani, S. (2013) 'The VFR Experience: 'Home' Away from Home?', Current Issues in Tourism 16(1): 1-15.

Sharpley, R. and P.R. Stone (eds) (2012) Contemporary Tourist Experience: Concepts and Consequences. Abingdon: Routledge.

Simmel, G. (1949) 'The Sociology of Sociability', The American Journal of Sociology 55(3): 254-61.

Somerville, M. and L. Hartley (2000) 'Eating place: Postcolonial explorations of embodiment and place', Journal of Intercultural Studies 21(3): 353-364.

Suvantola, J. (2002) Tourist's Experience of Place. Aldershot: Ashgate.

Therkelsen, A. (2015) 'Catering for Yourself: Food Experiences of Self-Catering Tourists', Tourist Studies 15(3): 316-33.

Tsai, C.T.S. (2016) 'Memorable Tourist Experiences and Place Attachment When Consuming Local Food', International Journal of Tourism Research 18(6): 53648. 
Uriely, N. (2010) '"Home" and "Away" in VFR Tourism', Annals of Tourism Research 37(3): 854-57.

Uriely, N. (2005) 'The Tourist Experience: Conceptual Developments', Annals of Tourism Research 32(1): 199-216.

Urry, J. (2002) 'Mobility and Proximity', Sociology 36(2): 255-74.

Urry, J. and J. Larsen (2012) The Tourist Gaze 3.0. London: Sage.

Van Nuenen, T. (2016) 'Here I Am: Authenticity and Self-Branding on Travel Blogs', Tourist Studies 16(2): 192-212.

Volo, S. (2010) 'Bloggers' Reported Tourist Experiences: Their Utility as a Tourism Data Source and their Effect on Prospective Tourists', Journal of Vacation Marketing 16(4): 297-311.

Wang, L. and P. Alasuutari (2017) 'Co-Construction of the Tourist Experience in Social Networking Sites: Two Forms of Authenticity Intertwined', Tourist Studies 17(4): 388-405.

Wang, Y., D.B. Weaver and A. Kwek (2016) 'Beyond the Mass Tourism Stereotype: Power and Empowerment in Chinese Tour Packages', Journal of Travel Research 55(6): 724-37.

Waskul, D., \& Vannini, P. (2006). Body/embodiment. Symbolic interaction and the sociology of the body. Aldershot: Ashgate.

White, N.R. and White, P.B. (2007) 'Home and Away: Tourists in a Connected World', Annals of Tourism Research, 34(1), pp. 88-104

Wijaya, S., B. King, T.H. Nguyen and A. Morrison (2013) 'International Visitor Dining Experiences: A Conceptual Framework', Journal of Hospitality \& Tourism Management 20: 34-42.

Williams, H.A., R.L. Williams and M. Omar (2014) 'Experiencing the Experience: An Examination of the Significance of Impact Factors During the Three Stages of Transnational Gastronomic Tourism', Transnational Marketing Journal 2(1): 21-37.

Wu, M.Y. and Pearce, P.L. (2014) 'Appraising Netnography: Towards Insights About New Markets in the Digital Tourist Era', Current Issues in Tourism 17(5): 46374.

Wu, M.Y. and Pearce, P. L. (2016) 'Tourism Blogging Motivations: Why Do Chinese Tourists Create Little "Lonely Planets"?', Journal of Travel Research 55(4): 53749. 